\title{
Impact of Whole Body Electromyostimulation with Nutrition Strategies on Body Composition in Overweight Adults: A Prospective Study
}

\author{
Elgabsi Zeineb ${ }^{1}$, Ayed Khadija ${ }^{2}$, Ksouri Riadh ${ }^{3}$ and Serairi Beji Raja ${ }^{1 *}$ \\ ${ }^{1}$ Department of Nutrition, High School of Sciences and Health Technics, Tunisia \\ ${ }^{2}$ Department of Physiology, Faculty of Medicine, Tunisia \\ ${ }^{3}$ Laboratory of Aromatic and Medicinal Plants, CBBC, Tunisia \\ *Corresponding Author: Serairi Beji Raja, Department of Nutrition, High School of \\ Sciences and Health Technics, Tunisia.
}

Received: July 08, 2021

Published: July 26, 2021

(C) All rights are reserved by Serairi Beji

Raja., et al.

\begin{abstract}
Purpose: Nutritional treatment and physical exercise are promising measures to prevent and treat obesity. However, conventional exercise is not always suitable for some patients due to unability to exercise conventionally. In this study, we examined the effect of a combined approach of the novel training method whole-body electromyostimulation (WB-EMS) and individualized nutritional interventions on anthropometric parameters and body composition in obese subjects after 12 weeks.

Methods: One hundred and twenty voluntary participants, aged $37.6 \pm 6.01$ years, were associated with the arms of the study according to eating habits:
\end{abstract}

- $\quad$ Control group WB-EMS SD ( $\mathrm{n}=30$ ) having continued their spontaneous feeding during the 12 weeks of study, without any attempt to balance it,

- WB-EMS BD group $(\mathrm{n}=30)$ followed dietary advice from the nutritionist in order to balance their diet both quantitatively and qualitatively,

- WB-EMS HP group $(\mathrm{n}=30)$ under a high protein diet with a daily protein of between 1.8 and $2 \mathrm{~g}$ per $\mathrm{kg}$ of body weight and

- $\quad$ *WB-EMS IF group ( $\mathrm{n}=30)$ practicing intermittent fasting with time limitation $(16 / 8$ method).

All participants were trained via the WB-EMS. A preliminary analysis of spontaneous food intake was made by a nutritionist with all participants: a 24-hour reminder. Body composition and weight were measured by Bio-impedancemetry. We similarly measured the waist and the hips circumferences using a tape measure. All measurements were made in triplicate. Data analysis was performed using BILNUT software and the SAS system.

Results: After 12 weeks of experimentation, results show that subjects belonging to the control group (WB-EMS-SD) significantly lost weight $(\mathrm{p}<0.05)$ and decreased their BMI $(\mathrm{p}<0.05)$. When body fat is expressed as a percentage of body mass, it significantly increased ( $34.04 \pm 7.57 \%$ vs $34.65 \pm 7.19 \%$; $\mathrm{p}<0.05$ ) while when expressed in $\mathrm{kg}$, it significantly decreased $(31.73 \pm 7.13 \mathrm{~kg} v s 30.15$ $\pm 7.94 \mathrm{~kg} ; \mathrm{p}<0.05$ ) between the start and the end of the experimental period. Skeletal muscle mass did not undergo any significant change ( $p>0.05)$. It is also for body water whether expressed as a percentage ( $>0.05)$ and in $\mathrm{kg}(\mathrm{p}>0.05)$. Compared to control group, participants in the WB-EMS-BD group lost more body fat $(-7.69 \pm 2.83 v s-1.57 \pm 1.76$; $\mathrm{p}<0.05)$ but gained more skeletal muscle mass $(1.68 \pm 1.31$ vs $-0.09 \pm 0.89 ; \mathrm{p}<0.05)$. As for the WB-EMS-HP group, they lost weight and decreased their BMI. Compared to the group without dietary intervention (WB-EMS-AS), the high-protein diet induced a greater loss in fat mass (-9.12 \pm 2.94 $v s-1.57 \pm 1.76)$ but did not allow preserve skeletal muscle mass $(-1.81 \pm 2.67 v s-0.09 \pm 0.89)$. Participants in the WB-EMS-IF group significantly reduced their weight $(\mathrm{p}<0.001)$ and their BMI $(\mathrm{p}<0.001)$. Body fat significantly decreased both when expressed as a percentage and in $\mathrm{kg}(\mathrm{p}<0.05)$. However, skeletal muscle mass and body water increased significantly.

Conclusion: Training by WB-EMS will be one of the best allies since it combines time saving and efficiency.

Keywords: Whole Body ElectroMyoStimulation; EMS; Nutrition; Obesity; Training; Dieting 


\section{Introduction}

Obesity is a chronic disease [1,2] defined by an excess of fat mass and is associated with an increased risk of diseases, in particular cardio-metabolic diseases such as type 2 diabetes [3], high blood pressure [4], cardiovascular diseases and cancers [5]. In 2010 , overweight and obesity were responsible for an estimated 3.4 million deaths worldwide, and some studies predict an increase in mortality associated with obesity [6]. Globally, the prevalence of overweight and obesity is $36.9 \%$ for men and 38\% for women [7]. In developed countries, the highest prevalence of obesity and overweight is reached at the age of 55 years in men $66 \%$ obesity and overweight, $25 \%$ obesity) and 60 years in women $(64,5 \%$ obesity and overweight, $31.3 \%$ obesity). In developing countries, obesity affects younger women at the age of 55 , but with a lower prevalence (14.4\%); as for men, they are the most affected by obesity at the age of 45 with a prevalence of $8.1 \%$ [7]. In addition, the countries having observed the strongest increase in the prevalence of obesity between 1980 and 2013 are Egypt, Saudi Arabia, the state of Oman, Honduras and Bahrain for women and New Zealand, Bahrain, Kuwait, Saudi Arabia and the United States for men [8]. Tunisia is not spared by this epidemic; obesity is a real public health problem. Indeed, this scourge progresses as well in adults and adolescents as in children and even the elderly. In 2005, obesity affected $37.0 \%$ of women aged 35 to 70 and $13.3 \%$ of men in the same age category, while overweight affected $73.1 \%$ and $51.7 \%$, respectively [9]. Coastal regions and urban cities are the most affected by this phenomenon. In 25 years, the prevalence of overweight has increased by $67 \%$ among adults aged $35-70$ and the prevalence of obesity has increased 2.5 times. The prevalence of obesity has doubled in men and tripled in women. Coastal regions and urban cities are the most affected by this phenomenon [10]. In the young population, Badr., et al. show that obesity is taking on seriously worrying proportions [11]. These authors, working on a population of 715 secondary school pupils, $53.3 \%$ of whom were female and $50 \%$ under the age of 14 , showed that among the participants, $23.5 \%$ were overweight (95\% CI [20,2\% - 26.7\%]), among them $17.4 \%$ overweight [95\% CI $(14.5 \%-20.3 \%)]$ and $6.1 \%$ obese [95\% CI $(4.4 \%$ $-7,8 \%)]$. In the elderly population over 65 years of age, the national study undertaken by Kammoun., et al. found an obesity prevalence of $15.6 \%$ [12]. Later, in 2009, a descriptive cross-sectional epidemiological survey involving a sample of 598 elderly people from the region of Monastir (Tunisia), showed that the prevalence of obesity was $49 \%$. In addition, it was more frequent in females $(59.3 \%$ vs
$28.5 \%, \mathrm{p}<0.001)$ and in subjects aged less than 70 years (60\% versus $29.3 \%$ in subjects older than 80 years old). The mean of body mass index was $31.4 \mathrm{~kg} / \mathrm{m}^{2}$ in women vs $27.9 \mathrm{~kg} / \mathrm{m}^{2}$ in men [13]. This considerable increase in the prevalence of obesity is the consequence of the social transition and the change in the nutritional habits in our country. In fact, the improvement in living conditions and the economic situation has led to a diet high in saturated fat, cholesterol and carbohydrates as well as a sedentary lifestyle.

Prevention is hardly developed while the role of behavioral, social and environmental determinants in the development of excess weight has been widely demonstrated [14].

Treatment for obesity is long-lasting and goes beyond a simple weight loss. Dietary protocols often give convincing results but are correlated with the extent of the energy deficit. So, the phase of caloric restriction is inevitable. In addition, the practice of physical activity is crucial. Its strengths have been widely demonstrated and its main objectives have been clearly identified: maintain muscle mass, increase in energy expenditure and basic metabolism rate, feeling of well-being, positive effect on the perception of the body. However, the constraints associated with this practice are obvious. Therefore, the use of alternatives to physical activity, combined with nutritional education of patients, could and should be considered as a new way in the management of obesity. In recent years, muscular electrostimulation has experienced a certain popularity in high-level sport circles. This process, known since the end of the $17^{\text {th }}$ century [15], aims to artificially stimulate the skeletal muscle using a low-voltage electric current from electrodes positioned on the surface of the skin. This artificial training method has the advantage of being completely harmless and not invasive while building muscle strength and endurance. Basically, it's mainly used in the medical and rehabilitation fields to treat many muscular illness [16]. Its field of application diversified greatly over the past twenty years [17]. Its contribution to fight against obesity has been the subject of many scientific discussion. A recent study on electrostimulation looked at weight loss in the prevention of cardiovascular disease and the area of health prevention [18]. The main objective of the study was to study the effect of electrostimulation, at different intensities, on energy expenditure (oxygen and calories). The results were conclusive, suggesting that electrostimulation can serve as an additional intervention in weight loss. Another recent study developed by Grosset., et al. examined the metabolic and cardiovascular effects of a one-hour lower extremity electrostimula-

Citation: Serairi Beji Raja., et al. "Impact of Whole Body Electromyostimulation with Nutrition Strategies on Body Composition in Overweight Adults: A Prospective Study". Acta Scientific Nutritional Health 5.8 (2021): 55-65. 
tion session and compared the cardiovascular response observed when walking in obese subjects [19]. Patients in the electrostimulation group developed greater lipid oxidation, so these results suggest that electrostimulation may be adapted to the obese population to induce an effective response to cardiovascular exercise [19].

Whole Body Electromyostimulation (WB-EMS) is considered as a time-saving, joint-friendly, and high customizable training approach that can be a perfect candidate for populations with low propensity for exercise [20]. Its positive effects on anthropometric parameters and body composition has been clearly demonstrated in athletes [21,22] and in sedentary overweight subjects [23].

Our primary objective is to examine the impact of WB-EMS, alone or combined with different dietary interventions, on body composition in sedentary obese or overweight subjects during 12 weeks. Our secondary aim is to determine, moreover, the diet adapted with efficiency to a WB-EMS training.

\section{Participants and Methods}

The study was planned and conducted between February and May 2019 in an electrofitness center in Tunis. Recruitment is done among the members of the center. The training programs are supervised by trained instructors.

\section{Participants}

Following our eligibility criteria for the screening assessment, we included (1) Volunteers, women and men aged from 28 to 55 years old, (2) Members of the center for WB-EMS training sessions, (3) Obese or overweight according to WHO criteria and we excluded participants with 1) total or partial amputation of the limbs and 2) contraindication for WB-EMS training (e.g. cardiac pacemaker). Accordingly, altogether 120 subjects (55\% men, 45\% women), aged $37.6 \pm 6.01$ years, were associated with the arms of the study. Factors preventing proper application of WB-EMS or parameters that may confound the study results were addressed. Thus, subjects were excluded if they: did not meet our criteria; reported contraindications to application of WB-EMS (i.e. total hip endoprosthesis, cardiac arrhythmia); took medication and/or suffered from diseases affecting our study endpoints; or said they would be absent for more than 4 weeks during the study period.

\section{Intervention}

Preliminary test: A preliminary analysis of spontaneous food intake was made by a nutritionist with all participants using a 24hour reminder. According to eating habits, we subdivide participants in 4 groups:

- $\quad$ A control group WB-EMS-SD ( $n=30)$ having continued their spontaneous feeding during the 12 weeks of study, without any attempt to balance it;

- WB-EMS BD group $(n=30)$ that followed dietary advice from the nutritionist in order to balance their diet both quantitatively and qualitatively;

- $\quad$ WB-EMS HP group $(\mathrm{n}=30)$ under a high protein diet with a daily protein of between 1.8 and $2 \mathrm{~g}$ per kg of body weight;

- WB-EMS-IF group $(\mathrm{n}=30)$ practicing intermittent fasting with time limitation (16/8 method).

\section{WB-EMS intervention}

We used WB-EMS equipment (miha bodytec ${ }^{\circledR}$, Gersthofen, Germany) that enables us to simultaneously stimulate thighs and upper arms, hip/bottom, abdomen, chest, lower back and upper back with an overall area of stimulation of about $2,600 \mathrm{~cm}^{2}$.

In the present study, all participants were trained via the WBEMS. In practice, a bipolar electric current has been applied based on the literature [24]. We used a frequency of $85 \mathrm{~Hz}$ and a pulse width of 350 beats per second with alternation between 4 seconds of rest and 4 seconds of electromyostimulation via WB-EMS devices manufactured by MIHA BODYTEC (Miha bodytec ${ }^{\circledR}$, Gersthofen, Germany).

The application of WB-EMS was done in a highly personalized training sessions with an instructor responsible for one or two participants.

The instructor started each WB-EMS session with an initial setting recorded in smart cards for each muscle group/region. Then, he increased the intensities slightly every 3 to 5 minutes until he reached a prescribed rate of perceived exertion (RPE). Due to regional and individual variations in current sensitivity, we used a rate of perceived exertion (RPE) to generate a sufficient but tolerable intensity of the EMS application. Participants were encouraged by the instructors to exercise at an RPE of "6 - 7" (i.e. hard+ to very hard) according to the Borg CR10 Scale [25]. 


\section{Assessment}

Tests were conducted at baseline and in the end of the experimentation consistently by the same methods. We have placed particular emphasis on the standardization of tests. They were performed by the same specialist before and after the period of intervention. Participants were asked to avoid any significant physical activity and to fast 3 hours before the assessment.

All the subjects included benefited from an anthropometric evaluation before and after our interventions using calibrated devices:

- Body size was measured with a "Seca 217 Stadiometer", barefoot or in socks, standing, points together and well balanced.

- $\quad$ Body mass index (BMI) was calculated as body mass/body height $\left(\mathrm{kg} / \mathrm{m}^{2}\right)$.

- Weight and body composition were determined by bio-impedancemetry using the "TANITA DC-430 MA" impedance meter. This method is based on measuring the body's resistance to the passage of electric current. The device used can determine body fat in kilograms and percentages, skeletal muscle mass and total body water [26,27].

- $\quad$ As for the circumferences, we measured the waist circumference as well as the hip circumference for each subject using a tape measure. The waist measurement was taken between the lower edge of the last palpable rib and the top of the iliac crest, with a tape measure placed horizontally, at the end of a normal exhalation [28].

All these measurements were made in triplicate. We used a detailed questionnaire covering various aspects including the general characteristics of the participants, medical and surgical history, physical limitations and lifestyle, in particular eating habits and behavior before and after the intervention. All these investigations were repeated in the end of the study in order to detect any changes.

\section{Statistical analyses}

Data analysis was performed using the following software:

- $\quad$ BILNUT: For entering dietary surveys and calculating total energy intake and carbohydrate, protein and lipid intake.

- The SAS system: For data entry and analysis.

We determined absolute frequencies and relative frequencies for the qualitative variables, means, standard deviations and deter- mined extreme values for quantitative variables.

Comparisons between the means and the percentages before and after the interventions were done by the Student's Test. Comparisons of the means on independent series were carried out by the ANOVA test. Comparisons of percentages on independent series were performed by Pearson's chi-2 test and, in the case of nonvalidity, by Fisher's test. All tests were two tailed, and significance was accepted at $\mathrm{p}<0.05$ respectively.

\section{Results and Discussion}

After weeks of experimentation, significant intragroup and intergroup differences were detected.

\section{Control group}

Figure 1 illustrates the variation in weight, BMI, waist circumference and hip circumference after 12 weeks of intervention via WB-EMS training in the group of subjects $(n=30)$ who continued their spontaneous feeding. We notice that the participants belonging to this group significantly lost weight $(94.17 \pm 14.38 \mathrm{~kg}$ vs 92.31 $\pm 14.29 ; \mathrm{p}<0.05)$ and decreased their BMI $\left(31.85 \pm 4.25 \mathrm{~kg} / \mathrm{m}^{2} v s\right.$ $\left.31.24 \pm 4.43 \mathrm{~kg} / \mathrm{m}^{2} ; \mathrm{p}<0.05\right)$. Their waist circumference as well as their hip circumference also decreased at the end of the experimental period, but this decrease was significant only for the hip circumference $(p<0.001)$. The ratio of waist circumference to hip circumference decreased from $0.961 \pm 0.054$ to $0.959 \pm 0.069$, but this decrease was not statistically significant ( $p>0.05)$.

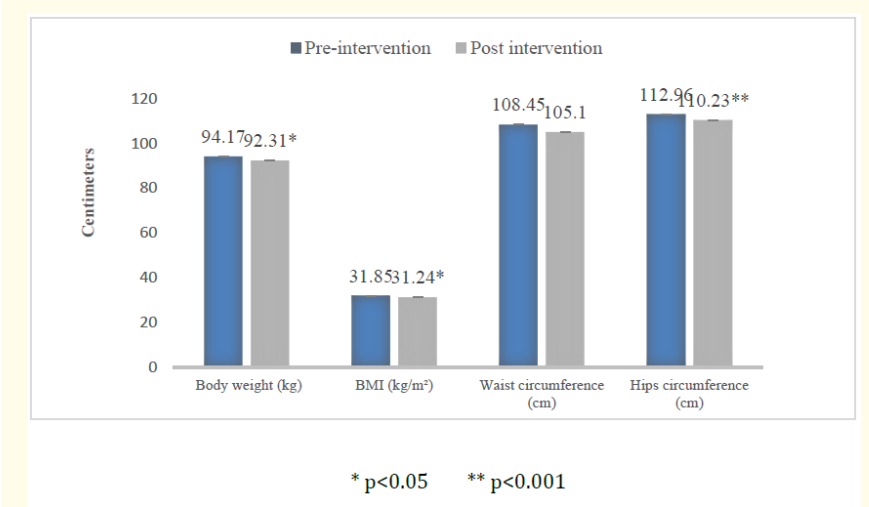

Figure 1: Effects of 12 weeks of WB-EMS on anthropometric parameters. 
The effects of the spontaneous intakes combined with WB-EMS on body composition are shown in table 1 . We notice that body fat significantly decreased when expressed in $\mathrm{kg}(-1.57 \pm 1.76 \mathrm{~kg} ; \mathrm{p}<$ 0.05 ) between the start and the end of the experimental period. Skeletal muscle mass did not undergo any significant change (-0.09 $\pm 0.89 ; \mathrm{p}>0.05)$. It is the same for body water whether it is expressed as a percentage $(+0.60 \pm 0.45 \% ; \mathrm{p}>0.05)$ and in $\mathrm{kg}(-0.24$ $\pm 1.45 \mathrm{~kg} ; \mathrm{p}>0.05$ ). The basal metabolism rate of the subjects included in this group decreased from $1820.6 \pm 405.1 \mathrm{kcal}$ to $1750.9 \pm$ $500.3 \mathrm{kcal}$ and this decrease is statistically significant $(\mathrm{p}<0.05)$.

\section{WB-EMS-BD group}

The subjects included in this group had, in addition to training via WB-EMS, a targeted intervention from the nutritionist in order to balance their diet. We can deduce that the weight and BMI of these participants significantly decreased at the end of the intervention period $(95.74 \pm 16.87 \mathrm{~kg} v s 89.05 \pm 17.05 \mathrm{~kg} ; \mathrm{p}<0.05$ and $30.99 \pm 4.28 \mathrm{~kg} / \mathrm{m}^{2}$ vs $29.65 \pm 4.52 \mathrm{~kg} / \mathrm{m}^{2} ; \mathrm{p}<0.001$ respectively) This weight loss is accompanied by a statistically significant decrease in waist circumference $(107.4 \pm 20.84 \mathrm{~cm}$ vs $103.6 \pm 10.75$ $\mathrm{cm} ; \mathrm{p}<0.05)$, hip circumference $(113,37 \pm 9.25 \mathrm{~cm}$ vs $106.13 \pm$ $9.91 \mathrm{~cm} ; \mathrm{p}<0.001$ ) and even in the ration waist circumference/ hip circumference $(0.947 \pm 0.168$ vs $0.977 \pm 0.062 ; \mathrm{p}<0.05)$ (Figure 2).

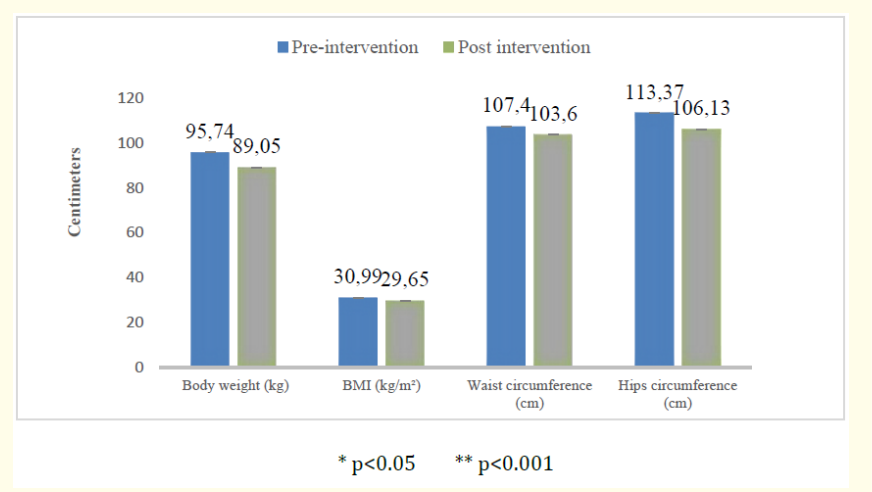

Figure 2: Effects of 12 weeks of WB-EMS combined with a balanced diet on anthropometric parameters.

Participants in this group received dietary support in order to balance their diet. We notice that the fat mass, expressed as a percentage, has significantly increased $(33.42 \pm 7.37 \%$ vs 36.07 $\pm 8.08 \%$; $p<0.05$ ) whereas it significantly decreased when ex- pressed in $\mathrm{kg}(31.33 \pm 6.07 \mathrm{~kg}$ vs $23.59 \pm 4.48 \mathrm{~kg} ; \mathrm{p}<0.05)$. Skeletal muscle mass significantly increased from $37.91 \pm 5.15 \mathrm{~kg}$ to $39.6 \pm$ $5.27 \mathrm{~kg}(\mathrm{p}<0.05)$. Body water, expressed as a percentage, significantly increased ( $41.05 \pm 6.7 \%$ vs $43 \pm 6.97 \%$; $\mathrm{p}<0.05)$, but decreased when expressed in $\mathrm{kg}(39.61 \pm 11.04 \mathrm{~kg}$ vs $38.37 \pm 10.1 \mathrm{~kg}$; $\mathrm{p}<0.05$ ) (Table 1). The basal metabolism of the subjects included in this group was significantly increased $(1939.6 \pm 442.1 \mathrm{kcal}$ to $1981.7 \pm 436.8 \mathrm{kcal} ;(\mathrm{p}<0.05))$.

\section{WB-EMS-HP group}

The subjects included in this group are, in addition to training via WB-EMS, on a high protein diet. Results of the evaluation of their anthropometric parameters are shown in figure 3.

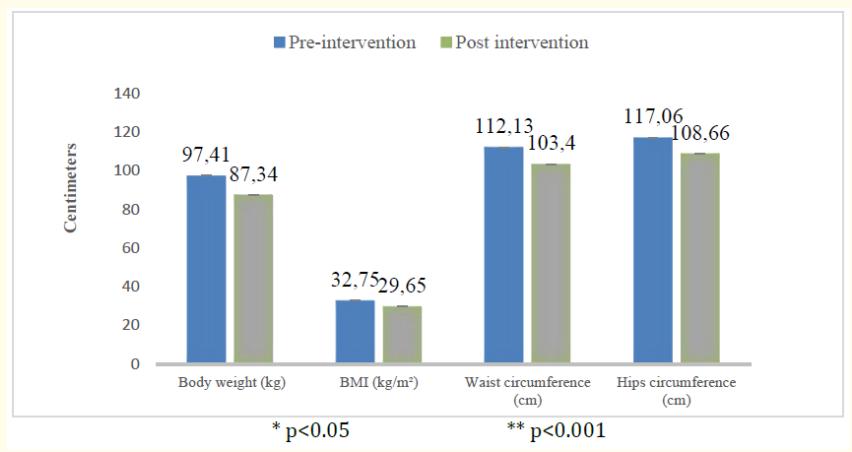

Figure 3: Effects of 12 weeks of WB-EMS combined with high protein diet on anthropometric parameters.

It appears that the subjects in this group lost weight (97.41 \pm $15.37 \mathrm{~kg}$ vs $87.34 \pm 15.62 \mathrm{~kg})$ and decreased their BMI (32.78 \pm $5.61 \mathrm{~kg} / \mathrm{m}^{2}$ vs $29.65 \pm 5.45 \mathrm{~kg} / \mathrm{m}^{2}$ ). Their waist circumference as well as their hip circumference also decreased (respectively 112.13 $\pm 12.19 \mathrm{~cm}$ vs $103.4 \pm 11.34 \mathrm{~cm}$ and $117.06 \pm 11.75 \mathrm{~cm}$ vs 108.06 $\pm 10.79 \mathrm{~cm}$ ). Variations in all of these anthropometric parameters are statistically significant $(\mathrm{p}<0.001)$. However, the modification in the ratio waist circumference/hip circumference ratio are not statistically significant $(0.957 \pm 0.037$ vs $0.957 \pm 0.048$; $p>0.05)$.

Our results reveal that the percentage on total body fat increased from $35.48 \pm 7.15 \%$ to $39.77 \pm 8.32 \%$ ( $<<0.05$ ), but it significantly decreased when expressed in $\mathrm{kg}(34.02 \pm 6.77 \mathrm{~kg} v \mathrm{~s}$ $25.09 \pm 7.21 \mathrm{~kg} ; \mathrm{p}<0.05$ ). Skeletal muscle mass decreased from $35.68 \pm 5.52 \mathrm{~kg}$ to $33.89 \pm 6.06 \mathrm{~kg}(\mathrm{p}<0.05)$. As for body water, it 
significantly increased and its percentage went from $39.68 \pm 4.34 \%$ to $44.28 \pm 4.63 \%(\mathrm{p}<0.05)$.

\section{WB-EMS-IF group}

Intermittent fasting (IF) for 12 weeks accompanied by training via the WB-EMS, resulted in a significant decrease in weight $(93.76$ $\pm 18.88 \mathrm{~kg}$ vs $87.43 \pm 12.67 \mathrm{~kg} ; \mathrm{p}<0.001)$, BMI $\left(31.88 \pm 4.28 \mathrm{~kg} / \mathrm{m}^{2}\right.$ vs $\left.29.71 \pm 4.13 \mathrm{~kg} / \mathrm{m}^{2} ; \mathrm{p}<0.001\right)$, waist circumference (109.23 \pm 11 $\mathrm{cm}$ vs $101.71 \pm 10.89 \mathrm{~cm} ; \mathrm{p}<0.001)$ and around the hips (112.2 \pm $14.45 \mathrm{~cm}$ vs $106.39 \pm 14.43 \mathrm{~cm} ; \mathrm{p}<0.001$ ) (Figure 4). It is also for the ratio waist circumference/ hip circumference $(0.982 \pm 0.078$ at the start of the experiment and $0.956 \pm 0.199$ at the end of the experimental period $(\mathrm{p}>0.05))$.

Total body fat has significantly decreased when expressed as a percentage $(36.56 \pm 5.28 \%$ vs $30.4 \pm 6.61 \%$; $<<0.05)$ or in $\mathrm{kg}$ $(34.13 \pm 6.19 \mathrm{~kg}$ vs $26.57 \pm 7.1 \mathrm{~kg} ; \mathrm{p}<0.05)$. On the contrary, skeletal muscle mass increased significantly, from $37.87 \pm 5.04 \mathrm{~kg}$ to $38.83 \pm 5.18 \mathrm{~kg}(\mathrm{p}<0.05)$. Total body water also increased significantly when expressed as a percentage (46.24 $\pm 9.4 \%$ vs $50.68 \pm$
9.4\%; $\mathrm{p}<0.05)$ and in $\mathrm{kg}(42.88 \pm 8.12 \mathrm{~kg}$ vs $43.69 \pm 8.03 \mathrm{~kg} ; \mathrm{p}<$ 0.05 ) (Table 1). The basal metabolism rate statistically increased from $1839.7 \pm 385.5 \mathrm{kcal}$ to $1867.9 \pm 185.5 \mathrm{kcal}(\mathrm{p}<0.05)$.

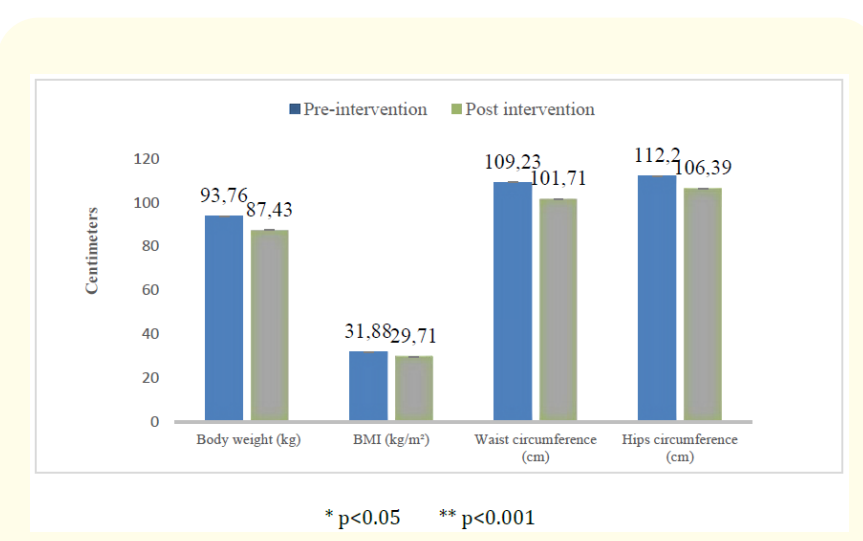

Figure 4: Effects of 12 weeks of WB-EMS combined with intermittent fasting (16/8 method) on anthropometric parameters.

\begin{tabular}{|l|c|c|c|c|c|}
\hline & $\begin{array}{c}\text { WB-EMS-BD } \\
(\mathbf{n}=\mathbf{3 0})\end{array}$ & $\begin{array}{c}\text { WB-EMS-HP } \\
\mathbf{( n = 3 0 )}\end{array}$ & $\begin{array}{c}\text { WB-EMS-IF } \\
\mathbf{( n = 3 0 )}\end{array}$ & $\begin{array}{c}\text { WB-EMS (CG) } \\
\text { (n= 30) }\end{array}$ & P- value \\
\hline Total body fat (\%) & $33.42 \pm 7.37$ & $35.48 \pm 7.15$ & $36.56 \pm$ & $34.04 \pm 7.57$ & \\
\hline Baseline & $-2.71 \pm 0.35^{*}$ & $-4.33 \pm 1.05^{*}$ & $-6.20 \pm 1.34^{*}$ & $0.56 \pm 0.77$ & $<0.001$ \\
\hline Changes & & & & & \\
\hline Total body fat (kg) & $31.33 \pm 6.07$ & $34.02 \pm 6.77$ & $34.13 \pm 6.19$ & $31.73 \pm 7.13$ & \\
\hline Baseline & $-7.69 \pm 2.83^{*}$ & $-9.12 \pm 2.94^{*}$ & $-7.57 \pm 2.83^{*}$ & $-1.57 \pm 1.76^{*}$ & $<0.001$ \\
\hline Changes & & & & \\
\hline Skeletal Muscle Mass (kg) & $37.91 \pm 5.15$ & $35.68 \pm 5.52$ & $37.87 \pm 5.04$ & $38.3 \pm 4.63$ & \\
\hline Baseline & $1.67 \pm 1.31^{*}$ & $-1.81 \pm 2.67^{*}$ & $0.97 \pm 0.21^{*}$ & $-0.09 \pm 0.89$ & $<0.05$ \\
\hline Changes & & & & \\
\hline Total body water (\%) & $41.05 \pm 6.7$ & $39.68 \pm 4.34$ & $46.24 \pm 9.4$ & $44.04 \pm 7.87$ & \\
\hline Baseline & $1.98 \pm 0.43^{*}$ & $4.65 \pm 0.24^{*}$ & $4.45 \pm 0.4^{*}$ & $0.60 \pm 0.45$ & $<0.05$ \\
\hline Changes & & & & \\
\hline Total body water (kg) & & & & & \\
\hline Baseline & $39.61 \pm 11.07$ & $38.65 \pm 5.18$ & $42.88 \pm 8.12$ & $41.47 \pm 9.82$ & $>0.05$ \\
\hline Changes & $-1.19 \pm 0.38^{*}$ & $-0.11 \pm 0.3^{*}$ & $0.81 \pm 0.36^{*}$ & $-0.24 \pm 1.45$ & \\
\hline
\end{tabular}

Table 1: Baseline values and changes after interventions in study groups

Note: ${ }^{*} \mathrm{P}<0.05 ; * \mathrm{P}<0.001$. 


\section{Discussion}

The present study demonstrated that both WB-EMS isolated and WB-EMS combined with individualized diets significantly affected obesity and overweight parameters.

First of all, it seems to us both interesting to study, in our context, the impact of WB-EMS without any nutritional intervention. This is the reason why we considered the control group. The subjects included in this group continued their spontaneous feeding. The food survey shows that their average spontaneous caloric intakes are of $2943.7 \pm 301 \mathrm{kcal}$, of which $46.4 \pm 11.7 \%$ in the form of carbohydrates, $41.2 \pm 8.3 \%$ in the form of lipids and $12.3 \pm 4.9 \%$ as protein. Compared to the recommendations of health authorities in terms of Nutrition, this diet is high in calories and unbalanced with predominance of fat to the detriment of carbohydrates.

Our findings show that the subjects belonging to this group significantly lost weight and decreased their BMI. Their waist circumference as well as their hip circumference also decreased at the end of the experimental period, but this decrease was only significant for the hip circumference $(p<0.001)$. The ratio of waist circumference to hip circumference fell from $0.961 \pm 0.054$ to $0.959 \pm$ 0.069 , but this decrease is not statistically significant ( $p>0.05$ ). All of these changes, mostly positive, could be induced by WB-EMS. Substantial evidence shows the benefits of exercise for at least 30 chronic diseases [30]. Moreover, data from old and actual literature describes resistance physical exercise as the best therapeutic agent for a sedentary population suffering from chronic diseases such as obesity and overweight [31,32] and even diabetes [33]. However, this type of exercise is very close to training based on WB-EMS, which would explain the improvement in the anthropometric parameters of the participants in this group. The results of the Bioimpedancemetry show that when body fat, when expressed in $\mathrm{kg}$, significantly decrease $(31.73 \pm 7.13 \mathrm{~kg} v s .30 .15 \pm 7.94 \mathrm{~kg} ; \mathrm{p}<0.05)$ between the start and the end of the experimental period. Skeletal muscle mass did not undergo any significant change. These results are supported by the statistically significant decrease in basal metabolism which fell from $1820.6 \pm 405.1 \mathrm{kcal}$ to $1750.9 \pm 500.3 \mathrm{kcal}$ $(\mathrm{p}<0.05)$. This positive impact of WB-EMS on total body and abdominal fat in obese or overweight subjects has also been found by Kemmler and Stengel [34]. These authors concluded that after 12 months of training with WB-EMS, there is an improvement in sarcopenia and decrease in visceral fat in older adult women. Recently,
Kiriscioglu., et al. showed that 8 weeks of training via the WB-EMS resulted in a significant decrease in weight of the participants, an improvement in their body composition and a decrease in body fat and BMI [35-54].

Several previous articles show that it is possible to modulate body composition by combining nutrition programs adapted to WB-EMS. This is the reason why we considered 3 groups of participants with different diets. The goal is to compare their effects in terms of body composition and anthropometric parameters.

In the WB-EMS-BD group, our intervention led to a significant decrease in weight and BMI $(95.74 \pm 16.87 \mathrm{~kg}$ against $89.05 \pm$ $17.05 \mathrm{~kg} ; \mathrm{p}<0.05$ and $30.99 \pm 4.28 \mathrm{~kg} / \mathrm{m}^{2}$ versus $29.65 \pm 4.52 \mathrm{~kg} /$ $\mathrm{m}^{2} ; \mathrm{p}<0.001$ respectively). These modifications result in a variation in body composition with in particular a decrease in body fat concomitant with an increase in skeletal muscle mass expressed in $\mathrm{kg}$. The percentage of body water has increased.

Compared to the control group, participants in this group lost more body fat $(-7.69 \pm 2.83$ vs. $-1.57 \pm 1.76$; $\mathrm{p}<0.05)$, but gained more skeletal muscle mass $(1.68 \pm 1.31$ versus $-0.09 \pm 0.89 ; p<$ $0.05)$. White adipose tissue, long considered an energy reserve tissue, is now recognized as an endocrine organ, which plays a role in the physiology of immunity and the pathophysiology of inflammation. It secretes hormones, such as leptin and adiponectin, as well as other molecules, collectively referred to as adipokines. These, produced directly by adipocytes or by macrophages infiltrating adipose tissue, induce a chronic low-intensity inflammatory state, which could play a central role, both in the cardiovascular complications of obesity and in insulin resistance, risk factor for type 2 diabetes $[55,56]$. These results corroborate those of Schink., et al. who show that after 12 weeks of testing with balanced food intake, subjects with cancer and trained via WB-EMS increased significantly their skeletal lean mass and body weight significantly compared to the control group [57]. The basal metabolism rate of the subjects included in this group increased significantly from 1939.6 $\pm 442.1 \mathrm{kcal}$ to $1981.7 \pm 436.8 \mathrm{kcal}(\mathrm{p}<0.05)$. This increase in basal energy expenditure can only be beneficial from a weight loss perspective. Another opportunity to remind and emphasize the benefits of a balanced diet.

The third group in which we were interested included subjects who made the choice to follow a high protein diet (WB-EMS-HP). 
Indeed, the food survey carried out before their inclusion in the group shows that their food intake is of the order of $1000 \mathrm{kcal}$, of which $12.5 \%$ in the form of carbohydrates, $15.5 \%$ in the form of fat and approximately $72 \%$ in the form of carbohydrates form of proteins. The results obtained show that the subjects included in this group are, in addition to training via WB-EMS, on a high protein diet. The results of the evaluation of their anthropometric parameters show that they lost weight $(97.41 \pm 15.37 \mathrm{~kg}$ against 87.34 $\pm 15.62 \mathrm{~kg})$ and decreased their BMI $\left(32.78 \pm 5.61 \mathrm{~kg} / \mathrm{m}^{2}\right.$ against $29.65 \pm 5.45 \mathrm{~kg} / \mathrm{m}^{2}$ ). Their waist circumference as well as their hip circumference also decreased (respectively $112.13 \pm 12.19 \mathrm{~cm}$ against $103.4 \pm 11.34 \mathrm{~cm}$ and $117.06 \pm 11.75 \mathrm{~cm}$ against $108.06 \pm$ $10.79 \mathrm{~cm}$ ). These variations are all highly statistically significant $(\mathrm{p}<0.001)$. Compared to the group without dietary intervention (WB-EMS-SD), it clearly appears that the high-protein diet induces a greater loss in fat mass $(-9.12 \pm 2.94$ against $-1.57 \pm 1.76)$, but does not preserve the skeletal muscle mass $(-1.81 \pm 2.67$ against $-0.09 \pm 0.89$ ). These results are supported by the decrease in their basal metabolism which goes from $1907 \pm 449.5 \mathrm{kcal}$ to $1889.6 \pm$ $449.9 \mathrm{kcal}$ ( $\mathrm{p}<0.05$ ). Kemmler., et al. [58] obtained comparable results with high protein intakes (1.7-1.8 g/kg/d), but lower than those consumed by our group of participants. Saïdi., et al. [59] also showed, in a population of young non-professional bodybuilders, that spontaneous and high protein intakes for 8 weeks do not induce a change in lean mass.

Fasting is an ancient practice, which is currently finding renewed interest in widely varying contexts: from religious rituals to medical practice, including the simple choice of life. The term fast encompasses several types of practice: complete fasting (only water is allowed), partial fasting (very modest caloric intake, around $300 \mathrm{kcal} /$ day), continuous fasting or intermittent fasting. Despite the paucity of randomized, controlled studies in humans, fasting therapy is often offered in certain chronic conditions, such as type 2 diabetes, high blood pressure and cancer. It is also practiced for losing weight in overweight or obese subjects. Its practice is not without risks and its effects are the subject of many controversy. In the present study, we considered a group that observed the intermittent fasting.

Intermittent fasting also called short time fasting consists of concentrating energy intake in a specific time interval (for example from 10 a.m. to 6 p.m.), which results in regular fasting periods. Participants (WB-EMS-IF) had a significant decrease in their weight ( $93.76 \pm 18.88 \mathrm{~kg} v s 87.43 \pm 12.67 \mathrm{~kg}$; $\mathrm{p}<0.001$ ), their BMI $\left(31.88 \pm 4,28 \mathrm{~kg} / \mathrm{m}^{2}\right.$ vs $\left.29.71 \pm 4.13 \mathrm{~kg} / \mathrm{m}^{2} ; \mathrm{p}<0.001\right)$, their waist circumference $(109.23 \pm 11 \mathrm{~cm}$ vs $101.71 \pm 10.89 \mathrm{~cm}$; $\mathrm{p}<0.001)$ and their hip circumference $(112.2 \pm 14.45 \mathrm{~cm}$ vs $106.39 \pm 14.43$ $\mathrm{cm} ; \mathrm{p}<0.001$ ). These anthropometric changes have their significance in terms of body composition. Indeed, body fat significantly decreased both when expressed as a percentage (36.56 $\pm 5.28 \%$ vs $30.4 \pm 6.61 \% ; \mathrm{p}<0.05)$ and in $\mathrm{kg}(34,13 \pm 6.19 \mathrm{~kg}$ vs $26.57 \pm$ $7.1 \mathrm{~kg} ; \mathrm{p}<0.05)$. In contrast, skeletal muscle mass and body water increased significantly. Numerous authors have quantified the effect of alternating fasting on body composition and waist circumference in pre-diabetic, obese, or overweight individuals [60,61]. The duration of the studies varied between 8 and 12 weeks. The mean reported abdominal circumference decreases ranged from 5 to $7 \mathrm{~cm}[62,63]$. By comparing this group (WB-EMS-IF) with the one who continued their spontaneous feeding (WB-EMS-SD), we notice that the decrease in mass fat is more important $(-7.57 \pm 2.83$ $v s-1.57 \pm 1.76$ ) as well as the sparing of skeletal muscle mass.

\section{Conclusion}

To sum up, our combined intervention of global electromyostimulation (WB-EMS) and dietary management through different types of diets demonstrates favorable promoting effects on body composition, anthropometric parameters as well as eating habits obese or overweight subjects after 12 weeks. Indeed, our intervention led to a significant decrease in weight and in fat mass with a gain in skeletal muscle mass in obese or overweight cohort. These findings imply that with encouragement to exercise regularly, as well as dietary guidance and advice, the positive impacts achieved by the WB-EMS training could be enhanced.

In short, the "ideal" diet for treating overweight and obesity and effectively adapted to overall electromyostimulation training is defined as safe, effective, healthy, nutritionally adequate, culturally acceptable and economically affordable. The most effective process for achieving long-term weight loss and cardio-metabolic health is, moreover, through a diet compatible with individual food preferences and lifestyle habits. This type of diet should have restrictions on added sugars, refined grains and highly processed foods and instead include fruits, vegetables, whole grain foods and low fat dairy products, not necessarily counting calories daily and should be combined with intensive nutrition education, motivation and behavior modification to achieve slow but steady weight loss and other health benefits. 


\section{Acknowledgements}

The authors would like to express their thanks for support from the ELECTROFITNESS CENTER "Bodytec Studio Tunis" and his founder "Ayed Anouar".

\section{Conflict of Interest}

The authors report no conflicts of interest in this work.

\section{Bibliography}

1. Willert S., et al. "Effects of Whole Body Electromyostimulation on the energy-restriction-induced reduction of muscle mass during intented weight loss". Frontiers in Physiology 10 (2019): 1012.

2. Ogden CL., et al. "Prevalence of childhood and adult obesity in the United States, 2011-2012". The Journal of the American Medical Association 311.8 (2014): 806-814.

3. Cheng HL., et al. "The health consequences of obesity in young adulthood". Current Obesity Reports 5 (2016): 1-8.

4. Collaboration BPLTT. "Effects of blood pressure lowering on cardiovascular risk according to baseline body-mass index: a meta-analysis of randomised trials". Lancet 385.9971 (2015): 867-874.

5. Calle EE and Kaaks R. "Overweight, obesity and cancer: epidemiological evidence and pro-posed mechanisms". Nature Reviews Cancer 4.8 (2004): 579-591.

6. Olshansky SJ., et al. "A potential decline in life expectancy in the United States in the 21st century". The New England Journal of Medicine 352.11 (2005): 1138-1145.

7. Ng M., et al. "Global, regional, and national prevalence of overweight and obesity in children and adults during 1980-2013: a systematic analysis for the Global Burden of Disease Study 2013". Lancet 384.9945 (2014): 766-781.

8. Matta J., et al. “Épidémiologie de l'obésité en France et dans le monde". La Presse Médicale 47.5 (2018): 434-438.

9. El Ati J., et al. "Gender obesity inequities are huge but differ greatly according to environment and socio-economics in a North African Setting: A National Cross-Sectional Study in Tunisia". PLoS ONE 7.10 (2012): e48153.
10. Insp Innta Msp. "Stratégie de prévention et de lutte contre l'obésité 2013-2017, programmation des actions". Surven Tunisie (2014).

11. Badr W., et al. "Prévalence de l'obésité et du surpoids chez les adolescents et association avec les facteurs de risques comportementaux Sousse, Tunisie 2016". The Annales d'Endocrinologie 79.4 (2018): 504-505.

12. Kammoun M., et al. "Diabète, hypertension, obésité chez les sujets âgés: étude à propos de 981 tunisiens âgés de 65 ans ou plus". La Revue de Geriatrie 31 (2006): 477-486.

13. Hammami S., et al. "La prévalence de l'obésité des personnes âgées en Tunisie". Middle East Journal of Age and Ageing 13.2 (2016): 3-9.

14. Sorensen TIA. "Challenges in the study of causation of obesity". Proceedings of the Nutrition Society (2008): 1-12.

15. Gondin J., et al. "Is high-frequency neuromuscular electrical stimulation a suitable tool for muscle performance improvement in both healthy humans and athletes?" European Journal of Applied Physiology 111 (2011): 2473-2487.

16. Ziltener JL and Chantraine A. "Méthodologie de la stimulation électrique fonctionnelle". Annales de Réadaptation et de Médecine Physique 40 (1996): 43-48.

17. Bax L., et al. "Does neuromuscular electrical stimulation strengthen the quadriceps femoris? A systematic review of randomised controlled trials". Sports Medicine 35 (2005): 191212.

18. Hsu MJ., et al. "Effect of neuromuscular electrical muscle stimulation on energy expenditure in healthy adults". Sensors 11.2 (2011): 1932-1942.

19. Grosset JF., et al. "Comparative effect of a $1 \mathrm{H}$ session of electrical muscle stimulation and walking activity on energy expenditure and substrate oxidation in obese subjects". Applied Physiology, Nutrition, and Metabolism 38.1 (2013): 57-65.

20. Kemmler W., et al. "Effect of whole-body electromyostimulation and / or protein supplementation on obesity and cardiometabolic risk in older men with sarcopenic obesity: the randomized controlled FranSO trial". BMC Geriatrics 18.1 (2018b): 70-75. 
21. Maffiuletti NA., et al. "The effects of electromyostimulation training and basketball practice on muscle strength and jumping ability". International Journal of Sports Medicine 21 (2000): 437-443.

22. Kots JM and Chwilon W. "Das muskel kraft training mit der methode der elektromyostimulation (russ.)". In: Die Anwendung der Elektrostimulation für das Training der Muskelkraft. Adrianowa GG, Koz JM, Martjanow WA, Chwilon WA (1974).

23. Kemmler W., et al. "Efficacy and safety of low frequency wholebody electromyostimulation (WB-EMS) to improve healthrelated outcomes in non-athletic adults. A systematic review". Frontiers in Physiology 9 (2018a): 573-579.

24. OMS: Organisation Mondiale de la Santé. International Classification of adult underweight, overweight and obesity according to BMI (2004).

25. Amaro-Gahete FJ., et al. "Changes in physical fitness after 12 weeks of structured concurrent exercise training, high intensity interval training, or Whole-Body Electromyostimulation training in sedentary middle-aged adults: A randomized controlled trial". Frontiers in Physiology 10 (2019): 451.

26. Zink-Rückel C., et al. "The use of whole body electromyostimulation (WB-EMS) as a golf warm-up - a randomized controlled cross-over study". Journal of Physical Health and Sports Medicine 2.1 (2019): 4-12.

27. Boulier A., et al. "Fat free mass estimation by two electrode impedance method". The American Journal of Clinical Nutrition 52.4 (1990): 581-585.

28. Modelesky CM., et al. "Density of the fat-free mass and estimates of body composition in male weight trainer". Journal of Applied Physiology 80.6 (1996): 2085-2096.

29. OMS. Waist circumference and waist-hip ratio. Geneva: World Health Organisation (2008).

30. Tsigos C., et al. "Management of obesity in adults: European clinical practice guidelines”. Obesity Facts 1 (2008): 106-116.

31. Jacobs EJ., et al. "Waist circumference and all-cause mortality in a large US cohort". Archives of Internal Medicine 170.15 (2010): 1293-1301.

32. Yong-Seok Jee. "The efficacy and safety of whole-body electromyostimulation in applying to human body: based from graded exercise test". Journal of Exercise Rehabilitation 14.1 (2018): 49-57.
33. Kemmler W., et al. "Effects of WB-EMS on resting metabolic rate, anthropometric and neuromuscular parameters in the elderly. The TEST- study". The Journal of Strength and Conditioning Research 24.7 (2010): 1880-1886.

34. Kemmler W., et al. "Impact of WB-EMS on body composition in elderly women at risk for sarcopenia: The TEST-III study (2013).

35. Fritzsche D., et al. "Elektromyostimulation bei kardiologischen patienten 35.1 (2010): 34-40.

36. Kemmler W., et al. "Effect of whole-body electromyostimulation and / or protein supplementation on obesity and cardiometabolic risk in older men with sarcopenic obesity: the randomized controlled FranSO trial". BMC Geriatrics 18.1 (2018c): 70-78.

37. Kemmler W., et al. "Whole-body electromyostimulation to fight sarcopenic obesity in community-dwelling older women at risk. Results of the randomized controlled FORMOsA-sarcopenic obesity study". Osteoporosis International 27 (2016): 3261-3270.

38. Day ML., et al. "Monitoring exercise intensity during resistance training using the session RPE scale". The Journal of Strength and Conditioning Research 18.2 (2004): 353-358.

39. Reddon H., et al. "The importance of geneenvironment,interactions in human obesity". Clinical Neuroscience Research 130.18 (2016): 1571-1597.

40. Jacobi D., et al. "Are we facing an obesity pandemic?" La Presse Médicale 39.9 (2010): 902-906.

41. Sacks FM., et al. "Comparison of weight-loss diets with different compositions of fat, protein, and carbohydrates". The New England Journal of Medicine 360.26 (2009): 859-873.

42. Anderson JW., et al. "Long-term weight-loss maintenance: a meta-analysis of US studies". The American Journal of Clinical Nutrition 74.5 (2001): 579-584.

43. Phelan S., et al. "Prevalence and predictors of weight-loss maintenance in a bi-axial cohort". American Journal of Preventive Medicine 39.6 (2009): 546-554.

44. Lluch A., et al. "Dietary intakes, eating style and overweight in the Stanislas Family Study". International Journal of Obesity and Related Metabolic Disorders 24.11 (2000): 1493-1499. 
45. Lecerf JM. “Obésité: pourquoi les régimes échouent-ils?” Nutrition in Clinical Practice 27.2 (2013) : 74-81.

46. Kotz YM. "Amélioration de la force musculaire par stimulation électrique, Terija i praktica fisiceskoj of kultury, 3-4, traduction Spivak, document INS, 874 (1971): 66-72.

47. Pedersen BK and Saltin B. "Exercise as medicine -evidence for prescribing exercise as therapy in 26 different chronic diseases". The Scandinavian Journal of Medicine and Science in Sports 25.3 (2015): 1-72.

48. Pedersen BK and Saltin B. "Données probantes sur la prescription d'exercices en tant que traitement des maladies chroniques". The Scandinavian Journal of Medicine and Science in Sports 16 (2006): 3-63.

49. Swedish National Institute of Public Health. Physical activity in the prevention and treatment of disease. Stockholm: SNI (2010).

50. Strasser B and Pesta D. "Resistance training for diabetes prevention and therapy: experimental findings and molecular mechanisms". BioMed Research International (2013): 805217.

51. Kemmler W and Stengel VS. "Whole-body electromyostimulation as a means to impact muscle mass and abdominal body fat in lean, sedentary, older female adults: sub-analysis of the TesT-III trial". Clinical Interventions in Aging 8 (2013): 13531364.

52. Kiriscioglu M., et al. "Effects of electromyostimulation training on body composition". Turkish Journal of Sport and Exercise's 21.1 (2019): 34-37.

53. Nanayakkara G., et al. "The cardio-protective signaling and mechanisms of adiponectin". American Journal of Cardiovascular Disease 2 (2012): 253-266.

54. Ellulu MS., et al. "Obesity and inflammation: the linking mechanism and the complications". Archives of Medical Science 13 (2017): 851-863.

55. Schink K., et al. "Effects of whole-body electromyostimulation combined with individualized nutritional support on body composition in patients with advanced cancer: a controlled pilot trial". BMC Cancer 18 (2018): 886.
56. Kemmler W., et al. "Whole-body electromyostimulation and protein supplementation favorably affect sarcopenic obesity in community-dwelling older men at risk: the randomized controlled FranSo study". Clinical Interventions in Aging 12 (2017): 1503-1513.

57. Saidi 0., et al. "Intake of carbohydrate-protein supplements by recreational users at gyms: Body composition improved?" Science and Sports 33 (2018): e141-e149.

58. Heilbronn LK., et al. "Alternate-day fasting in non-obese subjects: effects on body weight, body composition, and energy metabolism". The American Journal of Clinical Nutrition 81.1 (2005): 69-73.

59. Johnson JB., et al. "Alternate day calorie restriction improves clinical findings and reduces markers of oxidative stress and inflammation in overweight adults with moderate asthma". Free Radical Biology and Medicine 42.5 (2007): 665-674.

60. Klempel MC., et al. "Intermittent fasting combined with calorie restriction is effective for weight loss and cardio-protection in obese women". Nutrition Journal 11.1 (2012): 98-102.

61. Klempel MC., et al. "Alternate day fasting (ADF) with a highfat diet produces similar weight loss and cardio-protection as ADF with a low-fat diet". Metabolism 62.1 (2013): 137-143.

62. Aloui A., et al. "Effects of Ramadan fasting on body composition in athletes: a systematic review". Tunisie Médicale 97.10 (2019): 1087-1094.

63. Nematy M., et al. "Effects of Ramadan fasting on cardiovascular risk factors: a prospective observational study". Nutrition Journal 11.1 (2012): 69-71.

\section{Volume 5 Issue 8 August 2021}

(C) All rights are reserved by Serairi Beji Raja., et al. 